\title{
Evil Bert Laden: ViRaL Texts, Community, and Collision
}

\author{
James J. Brown, Jr.
}

In 1998, Dino Ignacio's website "Bert is Evil" won a Webby award for best "weird" website. The parody site placed the Sesame Street character Bert in a number of compromising situations by presenting doctored images of Bert at the site of John F. Kennedy's assassination, at KKK rallies, and alongside Hitler. Inspired by Ignacio's website, Dennis Pozniak circulated an image of Bert hovering over the shoulder of Osama bin Laden. Due to a hasty Google search by a company printing posters, this image of Bert alongside bin Laden was included on a protest poster used in Bangladesh. And so, Bangladeshi citizens protesting U.S. bombings in Afghanistan were waving signs that had Bert and bin Laden side-by-side-seemingly in cahoots. A Reuters photograph of the protest poster circulated via news outlets such as CNN and the New York Times, and the poster of Bert and bin Laden was seen by millions of confused Westerners. The image prompted a kind of hermeneutic fit from observers on message boards and various websites. One viewer of the image wondered whether it was terrorist code:"I wonder if it's some form of steganography to send a message to Al Quaida [sic] cells" (Lindqvist 2001). As Westerners looked closer, they saw other clues: "A closer scrutiny of one of the photos reveals a second apparent faux pas on the part of the radical Islamic protesters: Another clip art photo of bin Laden used in the photograph seems to show him with a bottle of Jack Daniels" (McCullagh 2001). This object turned out to be a knife. Such interpretive misfires continued in the days after this image surfaced as Western observers attempted to make sense of the jarring couple of Bert and bin Laden.

Even though the "Bert Laden" image was not on Ignacio's site, the image that Pozniak had circulated was inspired by the "Bert is Evil" site maintained by Ignacio. This prompted Ignacio to take down "Bert is Evil." Upon shutting down his site, Ignacio explained that Evil Bert had become too real: "I am doing this because I feel this has gotten too close to reality and I choose to be responsible enough to stop it right here" (Ignacio 2001). Pozniak had a different take: "You know, it's just a joke. It is a picture of Bert standing next to bin Laden. In no way do I see that it really has anything to do with the World Trade Center. It's just a picture of one guy standing next to another" (Pozniak qtd. in Blackwell 2001). Responses like Pozniak's were in the minority — many were disturbed by the image. Before the picture was traced to Ignacio's "Bert is Evil" site and Pozniak's handy work, many of these disturbed viewers attempted to decode this image. But, upon considering the circulation of this image-from Ignacio to Pozniak to various search engines to a printing company to Bangladeshi protesters to Reuters to Westerners dealing with the trauma of $9 / 11$ - we should consider what is behind the interpretive impulse. We might also consider whether interpretation can tell the entire story of ViRaL texts that situate reality chiasmatically between Virtual Reality (VR) and Real Life (RL). ViRaL texts make it extremely difficult to determine the meaning, the intention, or the reality behind a text. My argument here is not that we should give up interpretation when it comes to Web texts or any other kind of text. Interpretation is entirely necessary. And as we will see, many argue that our interpretive practices will have to change as we are forced to deal with ViRaL texts in a globalized, networked world. I see the value in this call for new methods of interpretation, but I am also interested in asking an additional question: What gets pushed to the side or forgotten in the interest of this hermeneutic impulse to decode?

When a ViRaL text is interpreted only in the interest of coherent meaning and intention, we miss an opportunity to re-examine the roots of the interpretive impulse. In addition to seeking out a particular meaning behind this kind of text, we might also recognize the importance of the very possibility that Bert and bin Laden can collide and 
collude on the Web. The Web's structure sets up a situation in which Bert and bin Laden can be in-community with one another, regardless of any choice on the part of Easterners or Westerners. These two images both collided and colluded. Regardless of the intentions of protesters or Ignacio, Bert and bin Laden worked together in whipping audiences into a frenzy. What does such a collision/collusion tell us about how community operates on the Web? How can our very understanding of community be expanded in a globalized, networked world? Traditionally, "community" has been understood in terms of collaboration and the conscious efforts of a group to "get together." However, the circulation of the Bert Laden image gives us a paradigmatic example of how such conceptions of community and collaboration can be expanded when we examine what is happening on the Web. Electronic collaboration is not necessarily confined to a concerted effort on the part of a well-defined community. This is certainly happening, but such conscious collaboration is only part of the story. The Bert Laden episode points out how community can also be something that happens to us. In the case of Bert Laden, there are all kinds of strange collaborations happening. Bert is working with bin Laden, Ignacio is working with Bangladeshi protesters, Sesame Street is working with al Qaeda. Such "teams" do not fit our traditional notion of collaboration or community, but they are a result of the structure of the Web-one that invites collisions that become collusions. Such a structure means that the reality of a ViRaL text is particularly shaky. For this reason, the hermeneutic impulse is entirely understandable as we attempt to pin down meaning. But this impulse happens in the face of a ViRaL text that reminds readers and writers that there is no clean separation between "us" and "them."

This essay re-examines the Bert Laden controversy and some of the discussions it triggered in order to pose a new set of questions about interpretation and community. The Web's structure is often credited with providing Web denizens with more opportunities to collaborate. In Here Comes Everybody, Clay Shirky argues that Web technologies tap into a human desire to connect and allow groups to form more easily: "By making it easier for groups to self-assemble and for individuals to contribute to group effort without requiring formal management (and its attendant overhead), these tools have radically altered the old limits on the size sophistication, and scope of unsupervised effort" (2008: 21). However, in addition to providing a space in which we can more easily form groups, the Web also invites a number of collisions. These collisions continually remind us that community, in addition to being the result of something we do, is also something that happens to us. Finding ourselves in-community with various others, we eventually separate off into communities that coalesce around common identities and interests. The Web will continue to allow for (and streamline) this sort of activity; however, it is the collisions that remind us that such conscious collaboration and coalescing happens only in response to our constant predicament of being in-community with a broad range of others. Upon colliding with these others, we immediately begin the process of interpretation: How am I the same as this other? How am I different? Is this other a member of my community? Are they an enemy? Can we make peace? Should we make war? These questions are unavoidable, but they stem from the collisions that we experience every day. Such collisions can be viewed as mere happenstance and as little more than a hiccup on the way to forming communities around common goals and identities. Or, these collisions can be viewed as a way to expand our notion of community so that it accounts for how collisions become collusions.

\section{"A New Hermeneutic"}

A number of scholars have examined the "Bert Laden" image controversy in attempts to understand our current cultural moment. These scholars seem to be in agreement that episodes such as this one will happen more and more frequently, and that educators and critics will need to help develop new interpretive methods and literacies. These new methods will have to come to terms with cultural and textual collisions and with ViRaL texts that remind us how difficult it is to contain a text. Upon shutting down the Bert is Evil website, Ignacio expressed concern that his parodies had "gotten too close to reality" and by this he meant that his website had been taken up by mainstream media. For Ignacio, the seemingly harmless combinations of a puppet with various iterations of evil were no longer innocent and contained-they had spread ViRaLly. Henry Jenkins points to Ignacio's concern about things getting too close to reality in order to proclaim a new paradigm: "Welcome to convergence culture, where old and new media collide, where grassroots and corporate media intersect, where the power of the media producer and the power of the media consumer interact in unpredictable ways" (2006:2). For Jenkins, collisions like the one between Ignacio's website and traditional media call for new methods of making sense of texts: "We need to find ways to negotiate the changes taking place. No one group can set the terms. No one group can control access and 
participation" (2006:23). Similarly, anthropologist David Pederson discusses responses to the image of Bert and bin Laden as evidence that globalized, networked societies require new "categories and methods": "in the largest of still-unfinished pictures, we continue struggling to find the appropriate categories and methods through which to... make sense of a changing world" (2003: 259). Mark Poster's discussion of Bert Laden joins this call for new methods of interpretation when he argues that the Web is a symptom of larger trends of globalization that impose "a new and heightened level of interaction between cultures" (Poster 2006: 9). For this reason, "the degree of autonomy of each culture is significantly reduced as a consequence of the global information network, and at the same time, the task of constructing a planetary culture is posed" (2006:9). This task of constructing a planetary culture leads Poster to ask whether we need a "new hermeneutic...that underscores the agency of the media" (10). I will return to Poster's discussion of building a planetary culture shortly, but for the moment I want to reiterate that all of these critics see the Bert Laden episode as an indication that the rhetorical environment has changed and that we need new interpretive methods.

These scholars are clearly on to something. As the image of Bert and bin Laden circulated, there was a strong desire to interpret the image and to domesticate the dizzying juxtaposition of Bert and bin Laden. The producers of Sesame Street made an immediate attempt to control their intellectual property:

Sesame Street has always stood for mutual respect and understanding. We're outraged that our characters would be used in this unfortunate and distasteful manner. This is not humorous...The people responsible for this should be ashamed of themselves. We are exploring all legal options to stop this abuse and any similar abuses in the future. (2001a)

Additionally, in the days after the publication of the photo, there was great concern about the effects of the image would have on children. The New York Times published a current events activity for grades 3-5 to help children make sense of the image (2001b). The quiz posed the six questions that any journalist would ask of this image: Who, What, When, Where, Why, How. The presentation of these questions to students indicates an overall feeling that the coupling of Bert and bin Laden would be somehow confusing or traumatic to young children. An open letter from Ignacio to fans of his site also expressed concern for the welfare of children. In fact, Ignacio explains his decision to take down the site as the killing of an internal child. Ignacio felt he was "kill[ing] the rebellious part of [his] soul... in lieu of the part that dictates to be responsible" (Ignacio 2001). He goes on to say that his main concern is that the site may destroy Bert's ethos:

my main motivation in killing the site is that $\mathrm{i}$ hope it helps stop the idea from germinating anymore into the mainstream. i fear that may destroy the character's credibility with children. i cannot allow that to happen. i myself grew up on sesame street and it was an important part of my childhood. (Ignacio 2001)

Ignacio and others were concerned that this ViRaL text would contaminate innocent children. The hermeneutic method of the New York Times current events quiz-who, what, when, where, why, how-was an attempt to provide children with the same method that Western adults had attempted to use to make sense of the image. Adults offered children an interpretive grid as a way of coping with the trauma of this ViRaL image.

This interpretive grid fell short of its goal to determine the meaning of the image. Far from being some larger commentary on U.S. popular culture, it was later reported that the Bert Laden image was the result of a careless Web search by the company making the protest posters. When creating the posters, the printing company searched the Web and combined a number of the images into a collage. The company included the Bert Laden image in its haste to print and sell the posters. There was no larger intention behind the image, no attempt to provide commentary about the pervasiveness and offensive nature of U.S. popular culture. But my interest in the Bert Laden image and the hermeneutic scramble that followed is not so much in interpretive failure. One of the great lessons of much contemporary criticism is that all interpretation falls short of any "final" goal. This failure to reach "the" interpretation is what keeps many of our disciplinary conversations going. Yet, beyond the short fallings of the various interpretive grids applied to Bert Laden, we might also take another lesson from the episode. That lesson requires a move beyond hermeneutics to a discussion of post-hermeneutic approaches, an expansion that allows us to reconsider what it means to confront various others online and offline.

\section{Interpretation and Community}

Poster's discussion of Bert Laden is worth pausing over. His discussion of the image opens up an ambitious 
conversation about how we might theorize and build a planetary culture based upon difference. While such a project offers us much in the current rhetorical environment-an environment that is often discouraging to those attempting to make peace-it might also miss an important lesson of the Bert Laden episode. That lesson is that attempts to build community are only part of what is happening online. While Poster attempts to understand how we might build a more peaceful and tolerant global community, the notion of community that the Web most starkly exposes is one that we do not necessarily choose. That is, the Web shows us that we are often in-community with those we might normally consider to be the enemy. This is one of the fascinating lessons of the Bert Laden image and the controversy that followed it. Bert and bin Laden on the same poster indicate an opening, the possibility for communication (and maybe even peace). But glimpsing such possibilities will require a rethinking of community. Understandings of community that are limited to communion or fusion — that is, communities built around essential identities and nationalisms - do not account for all of the collisions happening on the Web. Poster gestures toward this when he discusses how interpretive practices must change in a globalized, networked environment: "As never before, we must begin to interpret culture as multiple cacophonies of inscribed meanings as each cultural object moves across cultural differences" (2006:11). And in his attempts to redefine a planetary culture of differences and to re-work interpretive practices to fit that culture, Poster posits a new foundation for this new community. He argues that the "linkage of humans with machines" can act as "the cornerstone of possible new planetary cultures" (2006:24). By this view, we can build a planetary culture upon what we share-our linkableness. For Poster, what we share is that we all lie exposed and capable of linking to machines. This is his way of attempting to think community in an inessential way. No longer are we able to create clean, discrete communities based on essential identities. A networked, globalized infrastructure means that such clean separations are difficult, if not impossible. By pointing to the linkage of humans with machines, Poster theorizes a model of community that forces us to rethink issues of nationalism, identity, and communication.

Poster argues that Web technologies welcome "transcultural confusion" and that such technologies also "[create] the conditions of intercultural exchange that render politically noxious any culture which cannot decode the messages of others" (2006:11). It is with the use of this term "noxious" that we can begin to see the limits of his attempt to build or theorize a "planetary culture." This term is used multiple times in Poster's analysis of the Bert Laden incident and in his discussion of cultural collisions in general: "Just as the mixing of peoples within a nation renders especially noxious parochial ethnic and racial attitudes, so the mixing of cultural objects in the Internet compels each culture to acknowledge the validity, if not the moral value, of such objects that may be alien and other" (2006:21). In Poster's analysis, the word "noxious" seems to refer explicitly to strands of Islamic thought that posit Western popular culture as a contaminant to Muslim cultures. He cites Ali Asadullah's article "Spice Girls: Exactly the Reason Why Bin Laden Hates the West" as an example of such an outdated mode of thought that relies on monotheism and intolerance.[1] Asadullah's piece for IslamOnline.net was published a month after the attacks of September 11. In it, he argues that hatred of American popular culture is what fuels most radical Muslims. Asadullah expresses disappointment and disgust at a performance by a former member of the Spice Girls (Geri Haliwell) for British troops in Oman. For Asadullah, this event indicates a general lack of concern for Muslim culture and values: "in this time of delicate coalition and consensus building, one would have though [sic] that Britain's Foreign Secretary would have informed troops abroad to be on their very best behavior and not 'piss of the locals', as it were" (Asadullah 2001). Haliwell's performance is read by Asadullah and other Muslims as a slap in the face, and his description of Haliwell and her "bikini-babe dancers" as "so many trampy tarts" reveal how strongly he feels that Western popular culture is an encroachment on Muslim values. Asadullah's argument is that such encroachment is seen as a threat by many Muslims and that this threat leads to a vicious rhetorical feedback loop:

The issue at hand is the following: Muslims want their cultures, traditions and religious and societal standards to be respected. And those Muslims with extremely conservative or even radical views of the religion sometimes see disrespect in these areas as pretext for armed struggle. The sad thing is that the rhetoric from the West supports that pretext right now. It is rhetoric loaded with language that suggests that if Muslim culture isn't in step with a Western way of living and outlook on life, then it doesn't deserve to compete in the world's marketplace of ideas. (2001)

It is important to note here that Asadullah does not explicitly condemn those who turn to "armed struggle" to resist encroachments upon their culture. In fact, he points the finger at "the rhetoric from the West" when attempting to attach blame. That is, he points the finger at a "them" rather than an "us."

This willingness to point the finger outward (and only sometimes inward) is what seems to trigger Poster's response to Asadullah. Poster paints Asadullah as intolerant and argues that arguments about Western culture being 
offensive to Muslims are an example of the "politically noxious" stance of "any culture which cannot decode the messages of others" (2006:11). He argues that positions like Asadullah's are outdated and that globalization thwarts the attempts of any culture hoping to seal itself off from others: "Asadullah's position is exactly the logic that no longer works. With global networked digital communications, one must be especially careful in taking as an offense the legitimate cultural practices of another even if they are on one's own soil" (2006:22). For Poster, our current moment of globalization means that "the collective human intelligence embodied in the Internet is set in a deep cultural opposition to parochialism in general and to versions of monotheism in particular that refuse the condition of cultural pluralism" (2006:22-23). Building upon Jean-Luc Nancy's deconstruction of monotheism, Poster suggests that our current moment does not allow for the comfort of monotheisms:

The task of building a planetary culture that admits of differences rules out the comfort, if that is what it is, of a single deity, all-powerful, omniscient, reigning with love or with anger over the universe. If that is the case, then the Bert Laden incident is more than an amusing series of cross-cultural confusions but an allegory of changes in contemporary culture, pointing to conditions rife with profound political implications. (2006:24)

As Poster takes on the task of theorizing a planetary culture, he sees warring monotheisms as working against the structure of a globalized, networked world — a world that does not allow any single worldview to dominate.

As he expands this theory of community, we can begin to see the limits of Poster's planetary culture. His approach is in no way simplistic, and he points to our current globalized, networked society as a source of promise and difficulty. However, just as Asadullah looks outward rather than inward, Poster seems to make the same move. His focus is on the "harm" done by anti-American rhetoric: "Journalists and intellectuals such as Asadullah, with his smug air of moral repugnance at Western popular culture, do much harm in justifying the sentiments from which arose the hideous murders of September 11, 2001" (2006:22). Additionally, Poster is confused by critics who see "the imposition of the burqa on women" as anything but a "cause for critique" (2006:269). But just as Asadullah (mis)interprets Western popular culture as the culprit, Poster (mis)interprets monotheism as the root of the problem. It is in this attempt to look outward and interpret the Other that we see the danger of the hermeneutic impulse. Both Poster and Asadullah rely on this impulse alone in attempts to domesticate the opposing metonym. For Poster, Islamic fundamentalists (or, any kind of monotheism) will have to succumb to a network that renders their worldview "noxious." For Asadullah, Westerners will have to tone down their cultural practices if they hope to avoid angering various segments of the Muslim population. Such (mis)interpretations are not wrong. In fact, they are entirely unavoidable. In attempts to make sense of a jarring situation, Poster and Asadullah attempt to domesticate the other via interpretation. That is, they attempt to interpret the other in hopes of creating a better (and more peaceful) community. But these two critics are not talking about "others." They both are talking about an other that has already been interpreted, an other of which they have already made sense. The interpretive move is how we make sense of anything. When confronted with an unknown, we make use of an interpretive grid that allows us to categorize and ultimately control information. But this happens only after the traumatic recognition that we are exposed to the enemy's contamination prior to any choice on our own part.

Poster attempts to define an inclusive planetary culture, but his discussion reaches its limit in his clash with Asadullah. This clash — a clash that Lyotard might call a differend-results in Asadullah condemning all American popular culture and blaming it for Islamic fundamentalism and in Poster labeling Asadullah as part of a "politically noxious" stance that is a poor fit for the contemporary environment. But while Asadullah may be correct in his analysis of Islamic fundamentalists' reaction to Western popular culture and while Poster might be right that fundamentalisms and monotheisms are a poor fit for the current moment of globalization, we should take note of the price we pay for too quickly submitting to the interpretive impulse. Critiquing Poster's position proves to be somewhat counterintuitive as he is attempting to theorize an inclusive planetary culture. However, the rejection of fundamentalisms might provide too solid a foundation for his planetary culture. Poster may move too quickly beyond a key insight that Bert Laden gives us - that the Web exposes a community that "happens to us." Certainly, Web denizens are "building" communities, but they only do so after the experience a being-in-community with the enemy that the Web puts into relief. This experience is a being-in-community with those who we might normally consider to be the enemy. This is what is behind the trauma of Bert and bin Laden being side-by-side, a trauma that Westerners tried to manage by deciphering the code and learning the intention behind the image. As we later learned-and as Poster himself points out - there was no single intention behind the image.

Poster says that our current moment rules out monotheisms, but it's not clear that we can rule out anything or anyone. In fact, the most interesting, disturbing, and hopeful aspect of the current moment is that it welcomes 
a broad range of viewpoints, including fundamentalisms. That is, if the network is indeed forcing various culture clashes, many attempts to exclude will be inevitably thwarted. The difficulty of our current networked, globalized situation is that we are unable to exclude anyone in any final way. As we find ourselves in-community with various fundamentalisms, we find that laying the ground rules for a planetary culture that would exclude even the most violent and offensive fundamentalisms is impossible. We might link the limits of Poster's theory of community to his use of the term "planetary culture" and that term's implicit command that all follow the same set of rules. That set of rules for a planetary culture presents a ground, a foundation on which we can build community. However, the Web exposes something more than this, it exposes a community that we do not choose to build and that we do not "have." This community is what Nancy refers to when he says that "community, far from being what society has crushed or lost, is what happens to us" (1990:11, emphasis added). When Poster speaks of a planetary culture based upon our linkages to machines, he seems to be gesturing toward Nancy's discussions of finitude, "the infinite lack of infinite identity." This inability to claim any stable, essential identity is what we share, but it is not one more ground upon which we can build community. Instead, it is a groundlessness that puts us all in the same predicament. Nancy explains it this way: "finitude itself is nothing; it is neither a ground, nor an essence, nor a substance. But it appears, it presents itself, it exposes itself, and thus it exists as communication" (1990:28). Our exposedness to others shows itself in communication. When the Other confronts me, s/he provides a reminder that I cannot always decide which communications I will accept and which I will reject. Further, s/he reminds me that any attempt to define "my" community comes only in response to the community that happens to me-a community of collisions (collusions). We should remember that this is not a problem created by the Web. New technologies do not create a situation in which community happens to us, but they certainly provide a constant reminder of this predicament.

We might even think of the present essay as one more instantiation of how the Web puts opposing voices in community. As my Web text forces Poster and Asadullah to meet here at Fast Capitalism, we would most likely understand this as a confrontation — a face-to-face encounter in which these two metonyms for East and West engage dialectically.[2] However, such an understanding of this encounter would move too quickly beyond the notion that the Web puts Poster and Asadullah into community. Prior to being face-to-face in opposition, they are side-by-side in community experiencing (if indeed it is an experience on the level of cognition) what Nancy would call "something for which we have no name or concept, something that issues at once from a much more extensive communication than of a mere social bond" (1990:11). The community Nancy speaks of is the community we see happening on the Web, a community that happens to us and puts each of us into question. There is little doubt that Web denizens will continue to react to such situations by forming communities based around identities and shared goals, and this is not a bad thing. There is no way outside of such community, and a great deal of good work comes out of it. However, we are well-served to also see the concerted effort to "get together" as a response to that "something for which we have no name or concept." That is, in the face of a disorienting force that gives us to be we will need to create communities and get things done. But such communities can never be "universal" as Poster hopes, for the moment we attempt to create a universal planetary culture — even if that culture is grounded in difference-we run the risk of forgetting the exclusion inherent in any move toward community. It is not a matter of creating community without exclusion. It is a matter of recognizing that no created community is universal. If there is a universal (and I am not sure there is), it is the experience that Nancy gestures toward in The Inoperative Community, an experience that happens prior to and beyond the formation of an individual or a community. That experience is the one that puts us in community with others prior to any choice made on our part.

\section{| Post-hermeneutic}

It seems clear that attempts to make sense of Bert Laden relied on a distinctly "old" hermeneutic impulse to determine the meaning and authorial intention behind the image. Those attempting to decode this ViRaL image were assuming that a single, intentional author created the poster. Given such assumptions by a general public trying to decode this image, it is entirely reasonable that Poster and others would call for a new hermeneutic that recognizes the intentional fallacy and the complicated circulation of Web texts. But in addition to new interpretive practices, we may also need new understandings of community that attempt to slow our impulse to build an "us" in the face of alterity. If we move beyond hermeneutics to a post-hermeneutics, what else can we take from the image of Bert and bin Laden? What if it is not only, as Poster suggests, a new hermeneutic that is needed, but rather an understanding 
of what gets left out altogether by a hermeneutic impulse and the desire to get at the meaning of a text? As the Web introduces us to more texts and more others, we will undoubtedly feel the continued pressure to make sense of things. The structure of the Web sets the stage for the conversations that happen amongst Web denizens. Due to this structure, the Web provides us with a mass of text, and it invites a great deal of interpretative work. But the structure of the Web is important for another reason in that it invites an infinite number of writers. This structure forces us to confront a different kind of relation between readers, writers, and texts, and it frustrates any attempt to pin down stable, final meanings. It also points up a different and expanded notion of community.

The Web sets the stage for interactions between readers and writers in a way that traditional print does not. By inviting infinite writers to a seemingly endless conversation, the structure of the Web allows for ViRaL texts-texts that put different cultures and different realities into contact with one another. Such contact makes for what Diane Davis calls a "depropriative address" that is traumatic and contaminating. It is traumatic in that the address can exceed our attempt to "make sense" of things: "when you address me, no matter what you say to me, you expose in me a readiness to respond (a response-ability) that precedes both desire and will" (2005:200). The contamination of this address affects a self that is always radically exposed to another and response-able-open to a response prior to and beyond any intention to receive an Other. When Western viewers saw Bert (a metonym for a "West" with which they identified) alongside bin Laden (a metonym for Islamic fundamentalism that they considered to be the enemy), they were confronted with a trauma that called into question any clean separation between a community of "us" against "them." "Us" and "Them" were now side-by-side, and this ability to be side-by-side with the enemy is the contaminating effect of the ViRaL Bert Laden image. No longer able to maintain the notion (a fiction from the very start) that "We" are separate from "Them," Western viewers of the image were thrown for a loop. In this way, the coupling of Bert and bin Laden points up "a relation rather than an appropriation or assimilation, exposing a 'we' that is not a function of interpretation and that has nothing to do with commonality, reciprocity, or equality" (Davis 2005: 201). Such an experience of exposedness is a trauma that reminds us of our "extreme proximity and vulnerability" to any and all others (Davis 2005: 202). Given this reminder of vulnerability, it is entirely understandable that journalists and citizens began to apply various hermeneutic grids to the image. In order to deal with the trauma of exposedness — an exposedness that puts "Me" and "bin Laden" in the same community—readers of the image sought out an explanation.

Such searches for meaning via hermeneutic grids are not to be avoided and they are not "bad." As Davis and others have argued, it would be impossible (and damaging) to ditch interpretation. However, what Davis suggests (and what I am suggesting with a re-reading of the Bert Laden controversy) is that we attempt to account for the trauma that puts the hermeneutic gears into motion. Davis explains, via Lévinas, that trauma is where learning happens. For Lévinas, 'if it's really learning, then it is necessarily a trauma, a shattering of 'self' and 'world,' not an appropriation but an experience of depropriation and alteration from which there is no return. Learning, in Lévinas's lexicon, takes place via an encounter with the other, who, in addressing me, exceeds my thematizing powers and 'brings me more than I can contain"' (2005:199). And so we might read the image of Bert and bin Laden as a trauma that brought Westerners more than they could contain-something that would make the impulse to interpret and domesticate the image entirely understandable. Web pages and newspaper articles provided various interpretations and explanations of this image, and this hermeneutic scramble was a way to manage the trauma of the ViRaL image. Upsetting the comfortable boundary between "Us" and "Them," Bert Laden was an important learning moment. That moment was almost instantaneously lost in the move to interpret the image and massage the trauma. However, my aim in this essay is to return to that instant of learning. By returning to the trauma that triggered the hermeneutic impulse, we can re-read Bert Laden's ViRaL effect as a way to expand our traditional notions of community.

\section{Re-thinking Community}

The traumatic learning experience I am attempting to resuscitate gives us a way expand our notion of what "community" means. Beyond a collection of individuals who share beliefs and goals, community is also the collision we experience and the resulting collusions. The Web invites strange combinations-combinations that belong to no "one" and that do not necessarily represent any kind of concerted effort on the part of collaborators. When we think of collaboration, we might envision a cohesive group that slowly works toward a common goal. Yet, the Web allows for collaboration across space and time, collaboration that happens amongst people with different (and 
sometimes competing) agendas, and collaboration amongst those who never intended to be working together. As we have seen with the Evil Bert incident, when these competing groups recognized that they had collaborated, there was a good bit of recoil. The creators of Sesame Street were "outraged." A Reuters spokesperson claimed that the news service hadn't even noticed that Bert was on the poster until Fox News contacted it. Reuters responded "that it is definitely [their] policy not to doctor photographs" (Park 2001). And Ignacio was admittedly "freaked out" by the whole situation. We can read each of these startled reactions as a jolt to those who found themselves sleeping with the enemy.

On the Web and elsewhere, we don't always get to choose our collaborators, and we don't always have a say over who uses our texts. The Web does not create this situation, but it certainly exposes it. Yet, in addition to pointing us to the strange collaborations of the Web, the Evil Bert controversy might provide a bit of hope for the current rhetorical climate. If these two metonyms - Bert and bin Laden — can collaborate (however unwillingly) we might be able to see a sliver of hope for peace. The immediate response to such an argument might be that these two "systems" did not collaborate at all-they collided. And this is certainly true. But the very possibility of this collision (or, collusion) indicates the exposedness of which Davis speaks, an exposedness that points to a new way of understanding community. If we expand our definition of community beyond one of willing contributors and unified goals, we might be able to better formulate a road to peace. Such an understanding would point out that "we" are not cleanly separate from "them" - that each of "us" is exposed to one another prior to any conscious choice. Protestors in Bangladesh did not even notice Bert on their posters. He was, in essence, invisible until Westerners pointed him out. However, protesters participated in the circulation of this image nonetheless. The immediate response from the West was that the protestors found Western popular culture distasteful (this was likely true) and that they were making a political statement by placing Bert on the poster. However, what if we think of things differently: What if the very possibility that Bert and bin Laden can share space on a poster indicates the possibility for peace? What if it indicates that "we" are always exposed and readily contaminable by "them"? What if it indicates that there is no clean separation between us and them? This is one reminder of the ViRaL text.

Rather than attacking this image hermeneutically we might understand it as an indication of what collaboration on the Web really offers. In addition to offering a space where communities can gather toward particular goals (this, most definitely, is happening), the Web offers a place where community happens to us even without any sort of intentional gesture of "let's get together." What if the collision and collusion of bin Laden and Bert (and we should note here that they are not facing-off but are rather side-by-side, in community, facing us) indicates the possibility of an "unchosen" community? What if the combination of these two metonyms for East and West on a protest poster indicates not a community based on a formulated goal but a community of "incomparable ones"? This is the term Davis points to, once again channeling Lévinas:

'There must be a justice among incomparable ones,' Lévinas writes, and that means that the challenge is to compare without completely effacing the incomparableness of the 'we' that is exposed in the simple fact of the address; that is, the challenge is...to keep hermeneutic interpretation from absorbing the strictly rhetorical gesture of the approach, which interrupts the movement of appropriation and busts any illusion of having understood. (2005:208)

The very situation of symbolic exchange is an opening to the other regardless of the words that come out. These words may be hateful, dismissive, crude, disgusting. But regardless of content, we can, in some sense, view all discourse as an opening. Such an opening would not reduce Bert and bin Laden to sameness, and it would not proclaim that they have resolved their differences. But it might it start us down a road toward peace.

\section{Endnotes}

1. The "References" section of Poster's Information Please lists Asadullah's essay as being published on September 10, 2001, but such a date is impossible considering that the story references a performance by Gerri Haliwell for British troops in Afghanistan on October 6, 2001. Readers from outside the U.S. would recognize that the date on the site-9/10/2001- should be read as October 9, 2001. It may seem that I'm belaboring a small point, and it is not my goal to discredit an entire text based on a small mistake in the "References" section. However, I point to this very minor error to indicate that it is only the beginning of the misunderstandings that happen between the texts of Poster and Asadullah. 
2. In an interview in Giovanna Borradori's Philosophy in a Time of Terror, Derrida refers to "Bush" and "bin Laden" as overdetermined metonyms for East and West. I borrow this formulation here to discuss how Bert and bin Laden are stand-ins for East and West-standins that are presented as collaborators on the protest poster(Habermas, Derrida, and Borradori 2003).

\section{References}

2001a. "'Muppet' Producers Miffed Over Bert-Bin Laden Image." Accessed March 4, 2008 (http://archives.cnn.com/2001/ US/10/11/muppets/binladen/).

2001b. "News Snapshot: Osama and Bert." Accessed March 6, 2008 (http://www.nytimes.com/learning/teachers/snapshot/ student/20011015.html).

Asadullah, Ali. 2001. "Spice Girls: Exactly the Reason Why Bin Laden Hates the West." Accessed June 25, 2008

Blackwell, Tom. 2001. "Bert's New Buddy: Osama." Accessed March 4, 2008. (http://web.archive.org/ web/20011201203210/http://www.nationalpost.com/search/ story.html?f=/stories/20011012/731947.html\&qs=blackwell).

Davis, D. Diane. 2005. "Addressing Alterity: Rhetoric, Hermeneutics, and the Nonappropriative Relation.” Philosophy and Rhetoric 38:191-212.

Habermas, Jürgen, Jacques Derrida, and Giovanna Borradori. 2003. Philosophy in a Time of Terror : Dialogues with Jürgen Habermas and Jacques Derrida. Chicago: University of Chicago Press.

Ignacio, Dino. 2001. "Good-Bye Bert.” Accessed March 4, 2008 (http://web.archive.org/web/20020124023900/http://fractalcow.com/bert/).
Jenkins, Henry. 2006. Convergence Culture: Where Old and New Media Collide. New York: New York University Press.

Lindqvist, Nikke. 2001. "An Almost Cleaned Up Version of the Bert bin Laden Page.” Accessed June 25, 2008 (http:www. lindqvist.com/en/bert-bin-laden).

McCullagh, Declan. http://www.wired.com/politics/law/ news/2001/10/47450. 2001. "Osama Has a New Friend." Accessed June 19, 2008.

Nancy, Jean-Luc. 1990. The Inoperative Community. Minneapolis, MN: University of Minnesota Press.

Park, Michael Y. 2001. "Bin Laden's Felt-Skinned Henchmen?" Accessed March 4, 2008 (http://www.foxnews.com/ story/0,2933,36218,00.html).

Pedersen, David. 2003. "As Irrational as Bert and Bin Laden: The Production of Categories, Commodities, and Commensurability in the Era of Globalization." Public Culture 15:238-259.

Poster, Mark. 2006. Information Please: Culture and Politics in the Age of Digital Machines. Durham: Duke University Press.

Shirky, Clay. 2008. Here Comes Everybody: How Digital Networks Transform our Ability to Gather and Cooperate. New York: Penguin Press. 
